\title{
Las jícaras en el camino sagrado de los jóvenes iniciados Huicholes
}

Jerzy Antoni Mrożek Investigador Independiente

Antes de hablar con el fuego, es preciso postrarse ante el agua. La reverencia hecha hacia el agua como símbolo femenino que acompaña y protege al fuego, en el lenguaje religioso, funciona en muchas ocasiones como una presentación y como una solicitud de permiso. Para poder entrar de forma purificada, humilde y digna a la vez, para recibir un poder transformador hacia sí mismo y hacia la vida. La imagen es muy conocida y sigue presente a pesar de las modificaciones adquiridas en el tiempo y dependiendo de la cultura. Entrando, por ejemplo, a una iglesia católica, los feligreses se encaminan hacia el altar mayor, reluciente de oro. A la entrada encuentran una pila de agua bendita. En un acto de respeto y devoción los fieles tocan el agua con los dedos y llevan la mano hacia los cuatro puntos cardinales del cuerpo: el norte, el sur, el este y el oeste. Al finalizar este saludo ritual las manos se juntan, izquierda con derecha, en una modesta y conciliadora unión de los opuestos. Amén, que así sea.

En México católico de hoy se ha conservado, tal vez desde los tiempos medievales europeos, una tradición que nos remonta más allá de este simplificado gesto simbólico. El agua que a través de los dedos toca la frente, el plexo solar y los hombros, se une con la costumbre de permanecer un momento más largo frente a la pila. Este es el momento de comunicación, a través del pensamiento, de la intención y del verbo pronunciado, con el agua. Después de lograr esta sincronía, el agua se toma con la mano en forma de una cuchara para 
llevarla a la cabeza y soltarla desde arriba hasta abajo en un acto de ablución. Las dos manos siguen al agua escurriendo para untarla en el cuerpo, tocar los ojos, los labios, el cuello, los codos y las muñecas, las partes descubiertas en el momento ritual. En el nombre del Padre, del Hijo y del Espíritu Santo, con el permiso del agua, se puede seguir adelante, hacia el rumbo del este, donde tradicionalmente está ubicado el altar.

Pero en México profundo, que vive en las raíces del conocimiento y de la expresión religiosa, las cosas cambian, enseñando la pervivencia de símbolos arraigados a un nivel distinto, suspendidos en otra dimensión en referencia al tiempo y al espacio. Aquí, el altar mayor y su acceso no se encuentran al interior de un edificio amurallado y techado. La pila de agua bendita no está colocada a la entrada del sitio sagrado en función de la comodidad de los peregrinos. Para alcanzarlos se requiere de un gran esfuerzo, tanto físico como anímico. Para el grupo étnico de "hombres verdaderos" del Norte de México, los Wixaritari, que también se conocen como los Huicholes, el altar mayor es la montaña sagrada, al aire libre y bajo el cielo despejado. Allá, donde termina el horizonte, la sacralizan los rayos dorados del Sol naciente de la siempre primera y siempre eterna madrugada. La pila de agua son todas las aguas que rodean la montaña. Para llegar a ese altar, donde nace la luz, los peregrinos inician su andar desde la oscuridad de una cueva, mojada de agua, donde se guardan las vibraciones del universo. Desde este sombrío lugar en las entrañas de la Tierra caminan hasta el lugar de más claridad en la cima del monte. De esta manera se va marcando un camino de ascensión, desde lo más bajo, desde el dominio de las raíces, hacia lo más alto, en las esferas de las nubes. Los peregrinos empiezan así en el centro de la Tierra y forjan sus pasos por los cuatro rumbos cardinales, indicador de una ruta circular de crecimiento desde un interior hacia un exterior. Acompañan al sol en las cuatro estaciones del año, señalando un movimiento desde un antes hacia un después. Pasando por las montañas, las planicies, los bosques y los paisajes desérticos, todos ellos con sus aguas sagradas que otorgan permisos de entrada, se delimitan de manera irretornable un detrás de un adelante. El camino que así se construye de forma consciente hacia el altar, atravesando por las aguas que lo protegen, implica forzosamente una extensa topografía de lo sagrado y una cronología cíclica, anual, sin las cuales el camino queda incompleto. Porque, para ellos, para llegar a este lugar más alto y más luminoso del universo no hay un camino cómodo y fácil. No hay atajo, ni vía corta.

Entre los Indios Huicholes, pervive hasta tiempos actuales una antigua concepción de un caminar ritual en el sentido de "tejer". Durante todo el año, los peregrinos tejen así una red de caminos sagrados que los lleva paso a paso por las vivencias de creación y recreación teofánicas. No se puede ver de forma directa 
la cara de lo divino y sobrevivir. Por esta razón este tejido que sostiene a los que caminan, así como las experiencias presenciadas, son claves para poder acceder a niveles cada vez más iluminados, sin quedar ciegos, y cada vez más altos, sin caer en el intento. La peregrinación se vuelve la actividad principal durante todo el año y, para que pueda considerarse completa, se repite durante cinco años. Los que participan en ella se preparan con anticipación, practican ayunos y abstinencia sexual, dedicando su vida a labores religiosas, llevando ofrendas a lugares sagrados. Ellos se llaman xukuri'ikate, jicareros, una palabra que hace referencia a la jícara, un recipiente elaborado del fruto del árbol de tecomate o de calabaza. Partida a la mitad, la corteza del fruto toma forma de una vasija, sirviendo para tomar agua y para ofrecer bebidas (Fig. 1a-b).
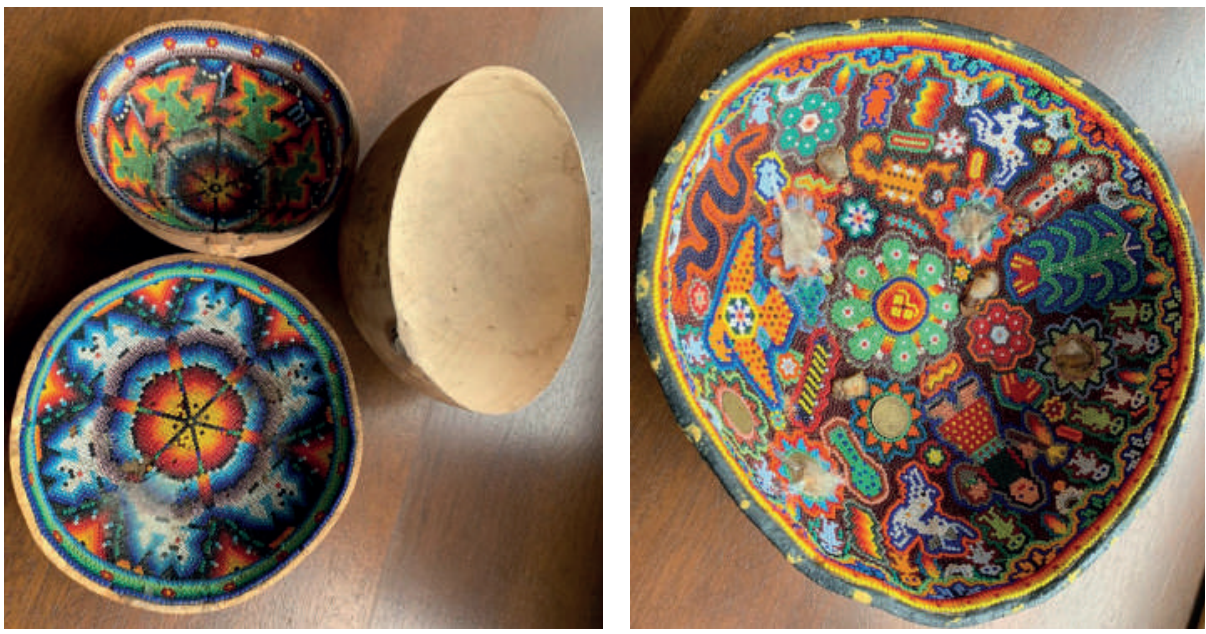

Fig. 1a-b. Jícaras votivas decoradas con cuentas de chaquira, monedas, plumas, etc. Fot. J.A. Mrożek, octubre 2009.

A los guardianes del templo de su comunidad, tukipa, cuando se convierten en peregrinos se les da el nombre de jicareros, "hombres - jícara", "los que toman agua en sus jícaras", "los que llevan jícaras", "los que llevan agua", "los que trabajan con las jícaras", "los que trabajan con el agua". Resulta interesante que son los hombres, en su mayoría jóvenes aprendices quienes, durante un largo y arduo camino hacia la morada del Padre Sol, portan el apodo repleto de símbolos femeninos de agua. Para poder visualizar esta relación, acompañemos a los jicareros por algunos lugares adonde llevan y donde dejan como ofrenda las jícaras. 
La peregrinación inicia en el centro del mundo, Tatiapa. Una cueva no muy lejana de las comunidades donde viven los Huicholes, en los actuales estados de Jalisco, Durango, Zacatecas y Nayarit, marca un tenebroso mundo de abajo, adonde llega todo aquello que muere y donde nace todo aquello que se proyecta hacia la vida. El punto de partida donde el iniciado peregrino viene a buscar entendimiento de las cosas, presentándose ante la eterna noche del inframundo. De las paredes húmedas de la cueva gotea el agua, acumulando charcos y creando hilos que escurren hacia los lados y hacia abajo. La cueva es una jícara primordial, donde se posan y de donde rebosan las aguas primigenias de las dos Abuelas, la monstruosa Abuela Nakawe: "la carne vieja" o "la que pudre carnes" y la Abuela Takutsi, la bondadosa diosa de la fertilidad.

El primer estudioso de la cultura Wixarika, Carl Lumholtz, describe este lugar de la siguiente manera:

En Tatiapa, mundo subterráneo, nuestras madres estaban ocupadas extendiendo sus esteras de junco en medio del agua primordial, las extendía al oeste, al sur, al este, al norte, y al medio. Se pusieron a crecer y su mundo se puso a crecer hacia el sur, el norte, el oeste, el este y en medio. En medio del agua crecieron nuestras madres llamadas 'La Nube que crece', 'La Diosa del Maíz', 'La que guarda el Maíz', 'La Diosa de la lluvia del este', 'La diosa de la lluvia Occidental', 'La lluvia del Sur', y todos los dioses del cerro y todos los demás, todos se pusieron a crecer, todos los dioses nacieron, además el Fuego, y el que prepara la milpa para sembrar el maíz. 'La abuela crecimiento' quien ha quedado completamente sola, se pone a crecer. Eso es lo que hicieron nuestras madres, se pusieron a agrandar su mundo, pero nacieron en Tatiapa. ${ }^{1}$

A ese mundo que nació de una jícara y que se tejió con los cabellos de la anciana más antigua, llegan los jóvenes Huicholes iniciando su camino de aprendizaje, llamado "camino de corazón". Aquí dentro, todo es femenino: la tierra, la cueva, el agua, la oscuridad. En la relación entre el peregrino y su lugar de la peregrinación, habitado por los dioses y las diosas, el nivel simbólico, intelectual, se juntan de manera inseparable con el nivel físico, sensual, un dualismo de extrema importancia en la comprensión de la estructura y funcionamiento del pensamiento prehispánico. El aprendizaje no es fruto de un esfuerzo intelectual, ni tampoco de una actividad física. Es fruto de su unión, donde las dos dimensiones, el pensar y el sentir, se reúnen en un acto de mutua entrega. El encuentro de las dos oscuridades da paso a la comunicación única, siempre no verbal, perteneciente al mundo mágico. La oscuridad propia del peregrino se ve reflejada en las aguas de la avasalladora oscuridad del lugar. La oscuridad exterior de la cueva se va apropiando desde las tinieblas de la oscuridad interior del

\footnotetext{
${ }^{1}$ Lumholtz 1989: 189-191.
} 
peregrino. Las oscuridades se tocan, se frotan, se entrelazan y se vuelven una. Esta unión de los opuestos, al interior de una cueva que aparece como útero, es la que permite el milagro de la fecundación. En un ritual evocativo del encuentro entre la vieja Nakawe y el abuelo Nairi, su esposo "el rayo de fuego", el peregrino se hunde en estas aguas, entrega todo su ser para recibir desde ahí mismo, desde el interior de la cueva, un tenue destello de luz, un nuevo brote de vida. Los peregrinos se postran de forma humilde ante esas aguas, depositan rezos y ofrendas para que los protejan en esta tarea: las jícaras, representando la cueva; las flechas, representando las serpientes; las veladoras, representando la luz. Con el permiso de las hijas de la Anciana, "Nuestras Madres", Tatei Uti'anaka y Tatei Yurianaka, se meten en una pequeña laguna $y$ pescan bagres para llevarlos de regreso a su comunidad.

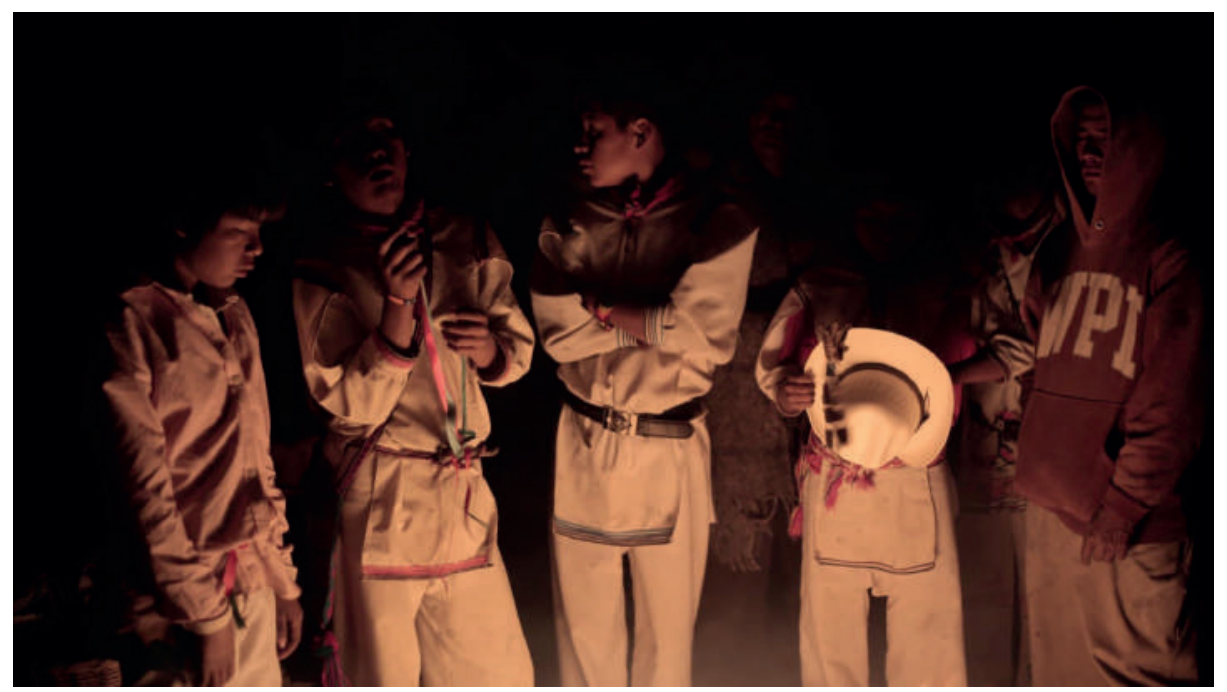

Fig. 2. Jóvenes jicareros participando en una ceremonia nocturna durante el inicio de la peregrinación. Fot. St. Cuske, marzo 2015.

\section{En el rumbo del Poniente habita Tatei Haramara, "Nuestra Madre" Dio-} sa del Mar. Acá, en la costa de San Blas, Nayarit, se juntan los dos ciclos, el ciclo anterior que muere y el ciclo nuevo que va naciendo. La parte occidental del universo es donde se esconde, donde muere y desde donde iniciará su regreso el Sol. Los jicareros atraviesan las aguas saladas del mar protegido por los manglares y llegan a una pequeña isla, Isla del Rey, donde, entre oraciones, cantos y sacrificios, dejan sus ofrendas. En la descripción de Robert Zingg, los Huicholes 
consideran que la tierra es un disco chato, al que rodea un mar poblado de serpientes acuáticas. El Padre Sol desciende todas las noches a este peligroso elemento lleno de serpientes, camina por debajo de él y de la tierra $y$, por la mañana, vuelve a elevarse al cielo con la ayuda de los loros que saludan la aurora con su ensordecedor clamor. ${ }^{2}$

Así para honrar las fuerzas del mar, después y previo a una ceremonia que se llevará a cabo du - rante toda la noche, en el momento de atardecer, los peregrinos mojan sus pies entre las olas y saludan la piedra blanca, una roca grande que sale del mar a poca distancia de la playa (Fig. 3).

De una o de otra manera, todas las aguas de la tierra y de las lluvias desembocan en los océanos, de donde, finalmente, nace la vida de los seres terrestres. Es otra jícara de dimensión geográfica, lejana e inmensa, llena de peligros y de esperanzas, que devora la vida para posteriormente dar vida a lo devorado. Esta relación, reflejante de una realidad percibida como un espejo dual, otra vez une los opuestos en una guerra que resulta ser una comunión.

Lo activo se vuelve pasivo y lo pasivo se vuelve activo, sin poder separarse. La luz se reconoce unida a la oscuridad, ambas fuerzas entrelazadas e interdependientes. El hombre, una isla rodeada y dependiente en cada momento del agua, percibe que esa agua también depende de su entrega, sus fuerzas, su cuidado y su trabajo. El conflicto pierde rasgos de oposición y adquiere cualidades de dependencia y cooperación en un acto transformador, inundado de mutuo respeto. Pedir favores y bendiciones de "Nuestra Madre del Mar" se vuelve, entre otras muchas cosas, una plegaria por el sustento durante la época de siembra de maíz:

El mar, que para la mente india rodea todo el mundo es, con su movimiento, ondulante, la más grande de todas las serpientes. Es la gran devoradora de todo. El sol tiene que hundirse, precipitarse, en sus abiertas fauces mientras el día se funde en la noche y todo se vuelve oscuridad. Y con él también los seres humanos desaparecen, atrapados por la serpiente. Pero por ser toda agua y la mayor de todas las aguas, la serpiente es la principal hacedora de nubes y, por consiguiente, también benéfica para los Huicholes. Se apela a sus poderes para producir lluvia. ${ }^{3}$

Es interesante notar, que es el trabajo del hombre, el que asegura el amanecer y se vale para ello de todos los elementos de su entorno cósmico que tenga a su alcance: las plantas, los animales, los fenómenos naturales, los astros. Sin el cumplimiento de la tarea por el hombre, los dioses pueden prescindir de él, como ya lo han hecho en la historia, cubriéndolo con aguas o matando con

\footnotetext{
${ }^{2}$ ZINGG 1982 2: 183.

${ }^{3}$ Lumholtz 1989: 121.
} 
rayos de fuego. En esta visión de intrínseca conexión de todos los elementos, las cosas solo funcionan dentro de una armonía primordial entre el hombre y el universo:

A veces las estrellas también figuran como acompañantes del sol y, una de ellas, Xuravemuieka, es la que debe matar con sus flechas a las serpientes del agua cuando a éstas les nacen las alas y pueden devorar a los hombres. ${ }^{4}$

Las fuerzas que permiten el equilibrio son las fuerzas que finalmente permitirán la perpetuación de la vida de todas las especies.

Fig. 3. Inmersión simbólica y bendición de las aguas del mar en la costa de San Blas, Nayarit. Abril 2013. Fot. K.A. Bielatowicz.

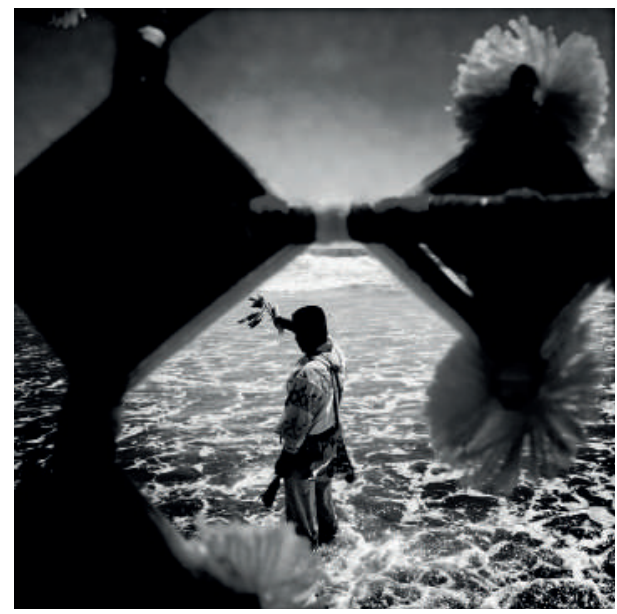

Cuando los peregrinos levantan su mirada hacia el Norte, se descubren nuevos horizontes de la vida espiritual. Hauramanaka, "lugar de la madera flotante", es el sitio sagrado identificado con este punto cardinal en el Cerro Gordo, Durango. Atravesando el bosque con sus ríos y arroyos los peregrinos llegan al lugar más alto de la montaña, cubierto de rocas. Aquí habita Ta - tei Haitsi Kipuri: "Nuestra Madre Cabello de Rocío", Diosa de la Lluvia septentrional. De todas las aguas, el agua de lluvia es considerada la más sagrada: viene del cielo, la acarician los divinos rayos de luz, cae en la tierra, la toca el viento. Permite descansar al Sol, va creando ríos y protege de las sequías.

El Norte es el rumbo donde duerme la noche, se aprenden los cuidados físicos y espirituales para proteger a la vida, se reponen las fuerzas requeridas para las labores de cosecha. Los primeros seres que salieron del mar, de noche, no eran seres de luz, no eran hombres. Eran lobos, sonámbulos seres nocturnos que no conocían más que el reflejo de luz por la luna. Vulnerables y desprotegidos, engañados y desconfiados, peleados con otros animales y fuertemente heridos, brutos y crueles, entregados a sí mismos y a su ciega sobrevivencia:

\footnotetext{
${ }^{4}$ Benitez 1968: 489.
} 
En el mundo inferior, 'los que han nacido' nacieron cuando todavía era de noche. Entonces, 'los que saben', cuando nacieron, dijeron: '¿Qué haremos para tener luz en nuestro mundo?' Primero nació la luna, su abuela, y tenía luz; pero ella los engañaba. ${ }^{5}$

Es en los fríos de la noche larga del Norte recibirán su instrucción, que les llegará a través de los sueños de su guía iniciado, mara 'akame, chamán, curandero y cantador, "el que sabe soñar". Es el lugar donde los primeros antepasados, que eran lobos,

mataban a sus hermanas lagartijas para ofrendar su sangre y comerlas crudas. Entonces Tatutsi Awexika les dijo que si querían encontrar su vida tenían que cazar y ofrendar la sangre del venado. Con mucho trabajo, dijo, haremos que el venado nazca. Entonces dibujaron un venadito con chaquira adentro de una jicara. ${ }^{6}$

Allí en el Norte los peregrinos aprenden que la muerte forma parte de la vida, y no hay vida sin muerte. Aprenden que la muerte es un acto sagrado, un acto de profundo amor al cual rendirle homenaje. Empiezan a cazar y aprenden a identificarse con su presa en una relación del cazador - cazado, donde la presa se entrega al cazador de la misma manera como el cazador se entrega a su presa adquiriendo con ella de esta manera un compromiso de por vida. En algún momento, al cabo de una larga preparación, cada uno de los peregrinos realizará su primer sacrificio, pidiendo perdón y permiso, con la finalidad de cumplir con su deber espiritual, reconociendo el vínculo inseparable entre lo recibido y lo entregado, entre la vida y la muerte. Al pedir por abundantes lluvias desde arriba de la montaña se pide por la fertilidad de la tierra, de los animales, de las mujeres y de los hijos, semillas del mundo. Que no falte fuerza para el cuerpo y para el alma, y que se renueve el espíritu. En el momento de más fervor religioso, de lágrimas, rezos y plegarias, la jícara se llena de sangre. A partir de este momento el líquido sagrado, portador de vida, acompañara a las ofrendas de los peregrinos en toda la red de sus caminos sagrados.

\section{Cuando termina la noche viene el amanecer, el momento de caminar rum-} bo al Oriente. Meses de preparativos anteceden la parte esencial de la búsqueda de luz, la visita al lugar donde nace el día, a este "mundo de arriba", en Wirikuta, cercano a Real de Catorce, en el estado de San Luis Potosí. A esa enorme jícara del semi-desierto, rodeada de altas montañas, que lleva rasgos orográficos de los antiguos mares, el venado soñado por el mara'akame trajo en otros tiempos a los primeros cinco cazadores. Entrando al desierto pasó por

\footnotetext{
5 Preuss y Dahlgren 1972: 116.

${ }^{6}$ Gutierrez del Angel 2010.
} 


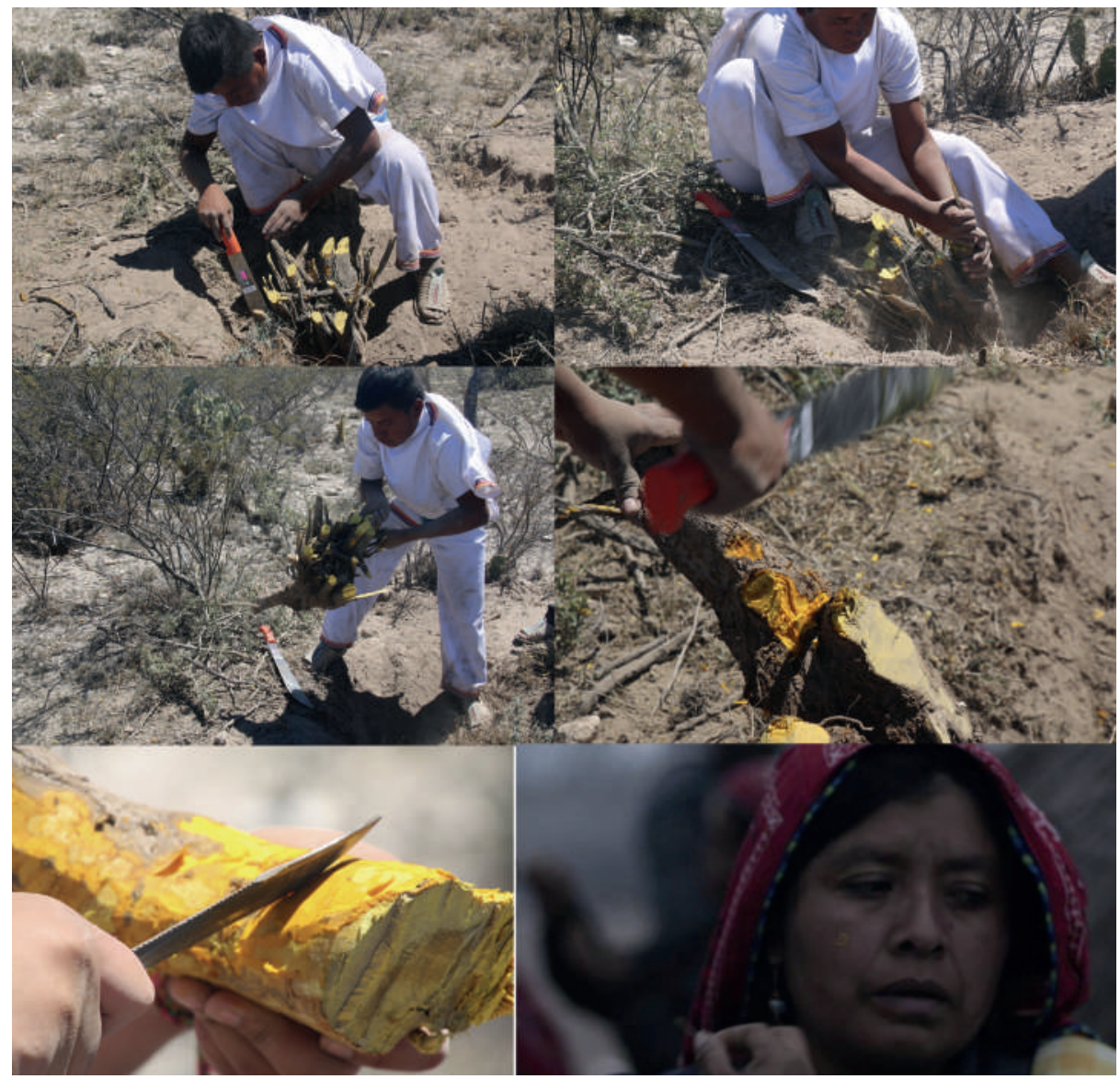

Fig. 4a-h. El jicarero encuentra y corta la raíz del árbol de uxa para la preparación de pigmento amarillo con el cual pintar las caras de los peregrinos con símbolos solares. Fot. J.A. Mrożek.

dos lugares, convirtiéndolos en oasis. Una de ellas, en una enorme planicie llamada Yoliatl contiene centenares de pequeñas pozas, fuentes de agua, cada una de ellas dejada por la pisada del venado, cuando este guiaba a los peregrinos. De las mismas pisadas crecerán después los peyotes, plantas visionarias del desierto. Aquí se realizan los ritos de confesión, purificación de consciencia, porque "si no dices todos tus pecados, te enfermarás en Wirikuta, te volverás loco y no encontrarás peyote". Aquí, en las aguas de los manantiales, habita otra de las cinco hermanas, "Nuestras Madres", Tatei Matinieri, Diosa de la Lluvia asociada al Oriente. En este lugar la Diosa Madre otorga el alma a los recién llegados. La introduce desde una jícara, a través de un chorro de agua vertido por 
la mollera de los recién nacidos. En este manantial rumbo a Wirikuta, hasta la actualidad, los peregrinos rezan, se purifican, se bautizan, dejan ofrendas y recolectan agua (Fig. 5).

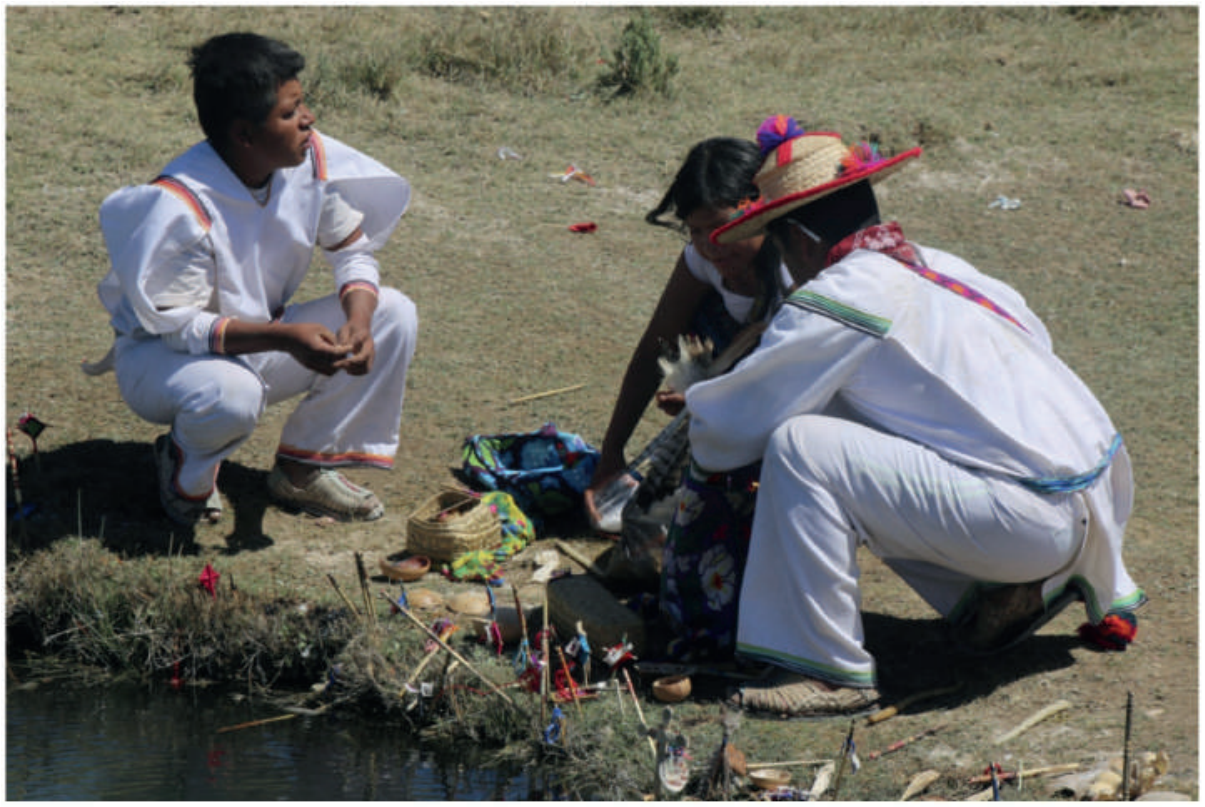

Fig. 5. Momentos comunitarios y familiares de entregar ofrendas en los sitios sagrados de Yoliatl y San Juan del Tuzal, fot. J.A. Mrożek, marzo 2017.

Un poco más adelante y cerca de la figura montañosa llamada Puerta, un lugar simbólico para ofrecer sacrificios y pedir permisos de entrada al desierto, se encuentran los manantiales de San Juan del Tuzal (Fig. 5). Rodeando los alargados cuerpos de agua crecen arbustos llamados uxa. Es un sitio de paraje obligatorio, llamado por los Wixaritari Tui Maye'u: "lugar de la pintura amarilla", la misma que se guardará en jícaras y se usará en la madrugada siguiente para pintar caras con símbolos solares (Fig. 4a-h). En este importante lugar de iniciación chamánica, los Huicholes recolectan las raíces de la planta junto con el agua de las pozas sagradas, ofreciendo a cambio tabaco, flechas, plumas, veladoras y jícaras decoradas con cuentas de chaquira.

Después de las noches de ceremonias y días de búsqueda del peyote en el desierto de Wirikuta, en una ceremonia de agradecimiento por la cosecha, las jícaras sirven de recipiente que sostiene las cabezas de los cactus divinos en un ritual ancestral de fraterno intercambio entre todos los peregrinos. El canto, el llanto y los gestos de un desbordante compartir del mara'akame, convertido en 
embajador de los dioses, conduce a los peregrinos bañados por los rayos del sol naciente hacia una realidad llena de luz interior, en un encuentro de dos luminosidades y su comunicación única, años luz más allá de la capacidad de expresión verbal. La luz propia se ve reflejada y se deja entender desde la avasalladora luz del lugar. La luz exterior llega a comprenderse y apropiarse desde el resplandor del propio corazón. Ambos esplendores se tocan, se frotan, se entrelazan y se vuelven uno. Esta unión de los opuestos, en el lugar reconocido como el más iluminado del universo, ocurre un gran milagro. El que hasta este momento recibía, se convierte en el que empieza a dar; el protegido se convierte en protector; el cuidado, en el que empieza a cuidar. A la familia, a la comunidad y a todo el universo.

El Sol que nace en el cielo es el que nace al mismo tiempo en el corazón del hombre. Muere un niño, un joven, un adolescente, para convertirse en el hombre adulto y maduro, en el padre, junto con el Padre Sol. La descripción de uno de los mitos más conocidos dentro de la mitología huichol, resuelve el proceso con una imagen de un sacrificio, simbólico y anímico a la vez:

En los principios del tiempo no había más luz que la de la Luna, lo que traía muchos inconvenientes a los hombres, reunieron entonces los principales de ellos para ver la manera de dotar al mundo de mejor luz, y le rogaron a la Luna que les enviase a su único hijo, muchacho enfermo, cojo y tuerto. Comenzó ella por oponerse, pero consintió al fin. Diéronle al muchacho un vestido de ceremonia, con sandalias, plumas y bolsas para tabaco; lo armaron de arco y flechas y le pintaron la cara, arrojándolo luego al fuego donde quedó consumido. Pero el muchacho resucitó, corrió por debajo de la tierra y cinco días después apareció como el Sol. ${ }^{7}$

Diferentes versiones del mito continúan describiendo la lucha posterior a esta transformación:

del fuego saltó un venado con plumas de águila; era el corazón del fuego.

El fue quien dirigió al niño hasta Reu'unar, allá en Wirikuta, era Tamatsi Wexika, quien sabe mucho y quien le iba a dar al niño su corazón iyari. Llevaba sus flechas y su carcaj para defender al Padre Sol. ${ }^{8}$

El sol recién nacido necesita protección, ya que

todos los animales nocturnos (los jaguares y leones monteses, los lobos, los coyotes, las zorras y las serpientes) se irritaron muchísimo y dispararon flechas contra el astro del día. ${ }^{9}$

\footnotetext{
7 Lumholtz 1989: 106-107.

${ }^{8}$ Gutierrez del Angel 2010.

9 Lumholtz 1989: 106-107.
} 


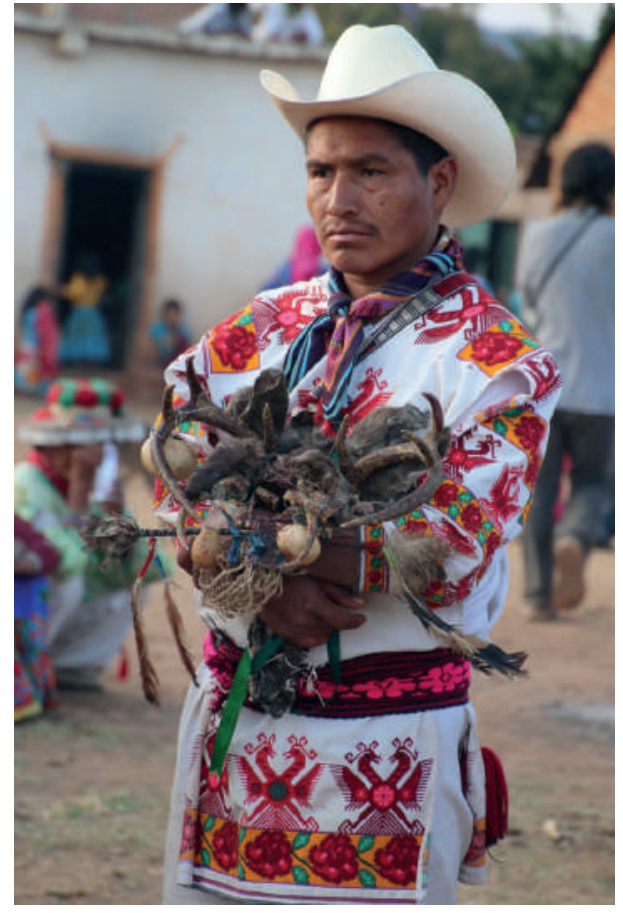

Fig. 6. Los jicareros con ofrendas de pieles de venados, cuernos de venados, veladoras y jícaras durante las fiestas en su comunidad, después de regresar del desierto Wirikuta. Fot. J.A. Mrożek, abril 2016.

Entonces la ardilla puso una jícara con la bebida de tejuino, lo que ayudó al nuevo sol a pasar y sobrevivir su primera noche, su primer viaje por el cielo. Cuando comió su primer peyote, el venado mítico, el primero que se dejó cazar por los peregrinos para que estos pudieran tener vida, el "Kauyumari pudo acercársele para levantarlo con sus cuernos" y "en este momento el sol se hizo grande y le tuvieron que poner una silla de mara'akate para que no se cayera". En una jícara "también le dieron de comer sangre y le colocaron unos pinitos". Después de un largo viaje, después de rendir homenaje a las aguas, pedirle permisos y buscar sus bendiciones, los peregrinos finalmente pudieron llegar desde el centro de la tierra al centro del universo, al lugar más alto, al lugar de la luz. Siguiendo los pasos de sus antepasados, llegando ante el altar mayor del Cerro Quemado, que se levanta por encima del desierto, han recibido la visión, para poder ver lo que es la vida.

En el desierto, el lugar más seco, es también donde nacen las lluvias. Los jicareros no paran en su camino, que termina sólo hasta que caiga el sol. La red de hilos de luz del tejido sagrado los lleva al rumbo del Sur. Allí habita "Nuestra Madre Higuera", Tatei Xapawiyeme, Diosa de la Lluvia, que tiene por su lugar de peregrinaciones la Isla de Alacranes en el Lago de Chapala, en el estado 
de Jalisco. En este lugar de aguas maduras dejan más plegarias por las lluvias abundantes y agradecen por todos los beneficios recibidos. Postrados con reverencia ante esa gran jícara del lago, los peregrinos depositan una vez más sus rezos y sus ofrendas para las madres protectoras del maíz y de las cosechas: las jícaras, representando las aguas de la laguna; las flechas, representando los rayos del cielo; las veladoras, representando el fuego.

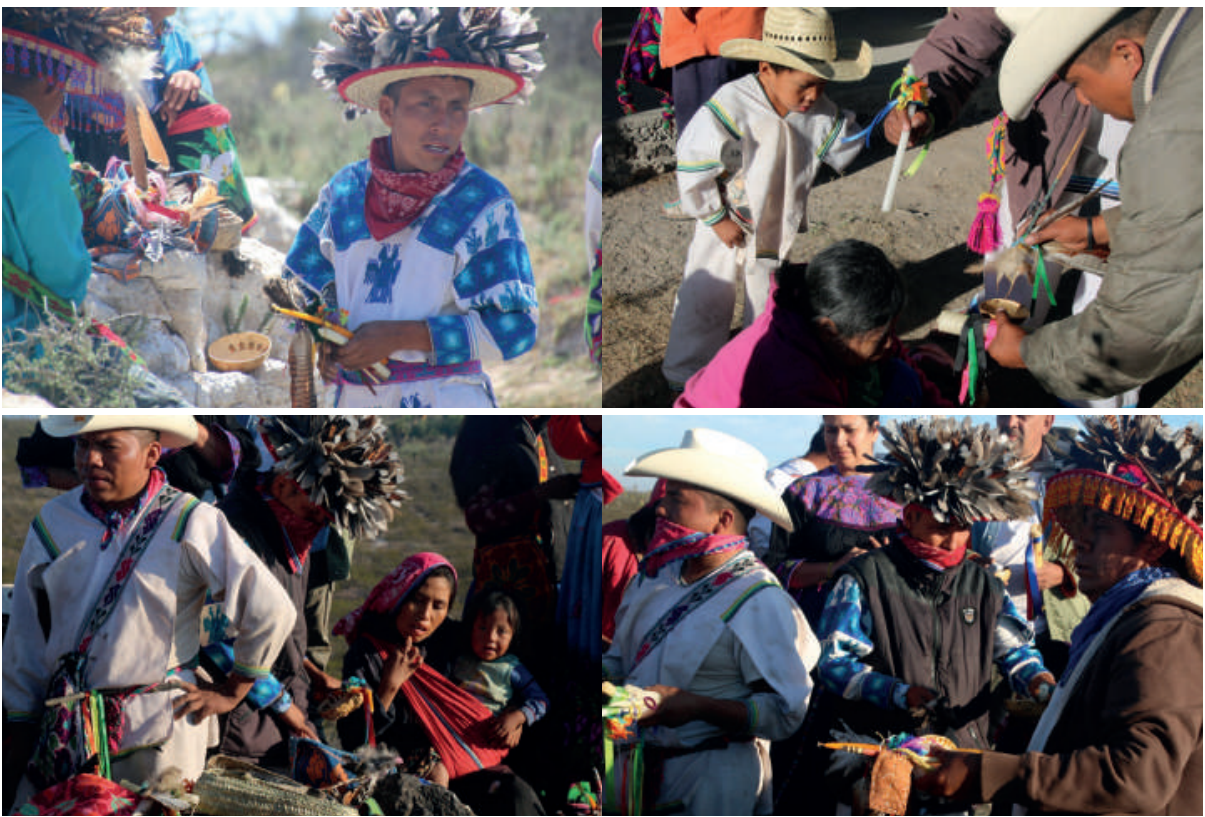

Fig. 7a-d. Los peregrinos preparan sus ofrendas de veladoras y jícaras, repartiendo bendiciones entre sus familiares y acompañantes. Fot. J.A. Mrożek, marzo 2017.

Así van y regresan a sus comunidades durante año tras año (fig. 6). En sus pueblos, caseríos y rancherías siguen con rituales, ceremonias, cacerías de venado, danzas y fiestas dedicadas a cada momento del ciclo solar, cada etapa del cultivo de la milpa, cada momento crucial de la vida familiar. Acá se mezclan, se entrelazan y se vuelven inseparables los elementos individuales y personales, comunitarios y sociales con ingredientes simbólicos cargados de fuerza y sentido de herencia universal, traídos desde los sitios sagrados lejanos.

Aquí termina y aquí vuelve a iniciar el eterno camino del matewame, "el que no sabe, pero que va a saber". La Abuela Vieja, la que en algún momento recibe todo lo que ha pasado por su ciclo de vida, la terrible y temible Nakawe recibirá la muerte para entregarla a la Abuela Takutsi, para transformarla en vida. Las dos van a esperar a otros jóvenes Huicholes, con quienes reiniciar la 
historia y a quienes permitir una vez más sacar la luz de la oscuridad y llevarla con conocimiento, con conciencia y con sensibilidad necesaria por todo el mundo.

\section{Bibliografía}

Benitez 1968 - F. Benitez, En la tierra mágica del peyote, México, ERA, 1968.

Benitez 1989 - F. Benitez, Los Indios de México, México, ERA, 1989.

Gutierrez Del Angel 2010 - A. Gutierrez del Angel, Las danzas del Padre-Sol. Ritualidad y procesos narrativos en un pueblo del occidente mexicano. México, Porrúa, 2010.

Lumholtz 1989 - C. Lumholtz, El México Desconocido, México, Instituto Nacional Indigenista, 1989.

Preuss y Dahlgren 1972 - K. Preuss, B. Dahlgren, Ensayos sobre Coras, Huicholes y Mexicanos, México, Instituto Nacional Indigenista, 1972.

ZINGG 1982 - R. M. Zingg, Los Huicholes: una tribu de artistas, México, Instituto Nacional Indigenista, 1982, Volumen 1 y 2

\section{Summary}

\section{The jicaras in a sacred path experience of the young Huichol initiates}

Among the Huichol Indians, an initiatory tradition has been preserved that consists of a series of five cycles of pilgrimages to the sacred desert. During their lives, each member of the commu - nity travels at least once to the desert, but young people who aspire to important positions within their group, dedicate ten to fifteen years to this task, during which they carry out countless religious activities. Within the dual indigenous conception of life, one of these activities consists of seeking and achieving an internal balance between the opposites. Through a symbolic element, a natural container for water, a jicara, the young apprentices are weaving a network of sacred paths towards achieving an organic equanimity between the two primordial forces that make up the universe: the masculine and the feminine. The article presents and accompanies the young $j i$ careros in the five main stopping places carried out during a pilgrimage cycle. From a cave, an underground jicara in the interior of the earth, to the sea, a huge jicara in constant contact with the sky, pilgrims deposit prayers and offerings in the vicinity of the bodies of water. In this way, through sensual contact with the vital liquid, water collecting in the jicaras, purification baths, and symbolic 
exchanges, acts of gratitude are carried out and permits are obtained to open access portals to major divinities, and finally, to the main altar of Cerro Quemado in the Wirikuta desert.

Keywords: Huicholes, Wixarica, Jícara, Cerro Quemado, Wirikuta

\section{Streszczenie}

\section{Rola jícaras w świętej ścieżce inicjacyjnej mlodych Huicholi}

Wśród Indian Huicholi pielęgnowana jest tradycja inicjacji, polegająca na odbyciu pięciu cykli pielgrzymkowych na świętą pustynię. Każdy członek społeczności musi choć raz w życiu udać się na pustynię, lecz młodzi ludzie, którzy aspirują do objęcia ważnych pozycji w grupie, poświęcają tym podróżom od dziesięciu do piętnastu lat, wykonując przy tym niezliczone czynności religijne. Jako że indiańska koncepcja życia ma charakter dualny, jedna z tych czynności polega na poszukiwaniu i osiągnięciu wewnętrznej równowagi między przeciwieństwami. Wykorzystując element symboliczny, jakim jest naturalny zbiornik wodny, zwany jícara, młodzi uczniowie tworzą sieć świętych ścieżek prowadzących do osiągnięcia organicznej równowagi między dwiema pierwotnymi siłami tworzącymi wszechświat: męską i żeńską. Artykuł przedstawia i towarzyszy młodym jicareros w pięciu głównych punktach, w których zatrzymują się oni podczas pielgrzymek. Od jaskini, jícary ukrytej we wnętrzu ziemi, aż do morza, ogromnej jícary pozostającej w stałym kontakcie z niebem, pielgrzymi wznoszą modlitwy i składają ofiary w pobliżu różnych zbiorników wodnych. W ten sposób, poprzez zmysłowy kontakt z życiodajnym płynem, wodą gromadzącą się w jicaras, w czasie kąpieli oczyszczających i symbolicznej wymiany darów, mogą oni wyrazić wdzięczność i uzyskać pozwolenie na wejście w kontakt z siłami wyższymi, aby w końcu dotrzeć do głównego ołtarza Cerro Quemado na pustyni Wirikuta.

Słowa kluczowe: Huicholowie, Wixarica, Jícara, Cerro Quemado, Wirikuta 